\title{
Ventral striatal dopamine synthesis capacity predicts financial extravagance in Parkinson's disease
}

\author{
Andrew D. Lawrence ${ }^{1 *}$, David J. Brooks ${ }^{2}$ and Alan L. Whone ${ }^{3}$ \\ 1 School of Psychology, Cardiff University, Cardiff, UK \\ ${ }^{2}$ Centre for Neuroscience, Department of Medicine, Imperial College London, London, UK \\ ${ }^{3}$ Department of Neurology, Frenchay Hospital, Bristol, UK
}

\section{Edited by:}

Alain Dagher, Montreal Neurological

Institute and Hospital, Canada

\section{Reviewed by:}

Oliver Pogarell, University of Munich, Germany

Alain Dagher, Montreal Neurological Institute and Hospital, Canada

*Correspondence:

Andrew D. Lawrence, School of Psychology, Cardiff University, Tower Building, Park Place, Cardiff CF10 3AT, UK

e-mail: lawrencead@cardiff.ac.uk
Impulse control disorders (ICDs), including disordered gambling, can occur in a significant number of patients with Parkinson's disease (PD) receiving dopaminergic therapy. The neurobiology underlying susceptibility to such problems is unclear, but risk likely results from an interaction between dopaminergic medication and a pre-existing trait vulnerability. Impulse control and addictive disorders form part of a broader psychopathological spectrum of disorders, which share a common underlying genetic vulnerability, referred to as externalizing. The broad externalizing risk factor is a continuously varying trait reflecting vulnerability to various impulse control problems, manifested at the overt level by disinhibitory symptoms and at the personality level by antecedent traits such as impulsivity and novelty/sensation seeking. Trait "disinhibition" is thus a core endophenotype of ICDs, and a key target for neurobiological investigation. The ventral striatal dopamine system has been hypothesized to underlie individual variation in behavioral disinhibition. Here, we examined whether individual differences in ventral striatal dopamine synthesis capacity predicted individual variation in disinhibitory temperament traits in individuals with PD. Eighteen early-stage male PD patients underwent 6-[ ${ }^{18}$ F]Fluoro-I-DOPA (FDOPA) positron emission tomography scanning to measure striatal dopamine synthesis capacity, and completed a measure of disinhibited personality. Consistent with our predictions, we found that levels of ventral, but not dorsal, striatal dopamine synthesis capacity predicted disinhibited personality, particularly a propensity for financial extravagance. Our results are consistent with recent preclinical models of vulnerability to behavioral disinhibition and addiction proneness, and provide novel insights into the neurobiology of potential vulnerability to impulse control problems in PD and other disorders.

Keywords: dopa decarboxylase, dopamine, disordered gambling, externalizing, impulse control disorders, impulsivity, reward, ventral striatum

\section{INTRODUCTION}

Several addictive and impulse control disorders (ICDs) have been associated with Parkinson's disease (PD) and its treatment with dopaminergic medication, including disordered gambling (Gallagher et al., 2007), substance dependence (Bienfait et al., 2010), and the addiction-like excessive use of dopaminergic medications, or DA dysregulation syndrome (Lawrence et al., 2003). The prevalence of ICDs in medicated PD patients was estimated at $\sim 14 \%$ in a large $(n>3000)$ multicentre study, with $>25 \%$ of affected individuals having multiple ICDs (Weintraub et al., 2010). The development of ICDs in PD likely results from an interaction between dopaminergic medication and an underlying vulnerability, rather than from PD itself, since: (a) only a (substantial) minority of medicated PD patients develop ICDs (Weintraub et al., 2010); (b) ICDs are no more frequent in patients with de novo PD than in the general population (Weintraub et al., 2013); (c) ICDs can develop in non-PD individuals treated with dopaminergic medication (O'Sullivan et al., 2010; Voon et al., 2011a); and (d) a family history of gambling problems is a risk factor for the development of dopaminergic medication-linked ICDs (Weintraub et al., 2010; Voon et al., 2011a).

This precursive ICD vulnerability likely reflects variation in preexisting temperament/personality (Dagher and Robbins, 2009), in particular, variation in the broad temperament dimension of trait disinhibition (vs. constraint), encompassing impulsivity, novelty/sensation seeking, non-planning, low self-control, and related constructs (Markon et al., 2005). In PD, just as in non-PD populations (Sher and Trull, 1994; MacLaren et al., 2011), phenotypic associations between trait disinhibition and substance use and ICDs (and their comorbidity) have been repeatedly demonstrated (Evans et al., 2005; Voon et al., 2011b).

These findings suggest etiologic similarities between ICDs and addictions in PD and the broader domain of externalizing (EXT) psychopathology in non-PD populations (Krueger et al., 2007). Patterns of phenotypic, environmental, and genetic relations among DSM-defined substance misuse and antisocial disorders are best accounted for by models positing a shared broad EXT factor or vulnerability (Krueger et al., 2007). I.e., putatively distinct disorders are better understood as variants within a broader 
EXT spectrum of disorders, and the reason they systematically co-occur is because they share a common underlying genetic vulnerability (Krueger et al., 2007). This broad EXT vulnerability is a continuously distributed dimension of risk (Krueger et al., 2007). Hierarchical models of the EXT spectrum (Krueger et al., 2007) posit a general factor linking all EXT syndromes, as well as distinct etiological factors that differentiate among distinct EXT syndromes. Disordered gambling, frequently comorbid with substance abuse and antisocial personality disorder (Kessler et al., 2008) is also considered one variant of EXT (Oleski et al., 2011; Blanco et al., 2012; Forbush and Watson, 2013; but see Slutske et al., 2013).

A shared genetic diathesis underlies the phenotypic associations between EXT disorders and disinhibited personality traits, including novelty seeking (NS; Young et al., 2000; Agrawal et al., 2004). Furthermore, prospective studies suggest that high levels of these traits in childhood and adolescence predate and predict the emergence of EXT psychopathology in adulthood (Sher et al., 2000; Slutske et al., 2012). I.e., the temperamental antecedent of disinhibition provides the core endophenotype of EXT disorders (Clark, 2005), mediating their systematic co-variation (Khan et al., 2005). Hence, understanding the genetics and neurobiology of disinhibitory personality traits is critical to understanding EXT psychopathology, including its manifestation in the context of PD and its treatment with DA replacement therapies.

The DA system has frequently been hypothesized to underlie individual variation in trait disinhibition. According to one prominent model (Pickering and Gray, 1999), individual differences along this temperament dimension are argued to reflect variation in the reactivity of a neural behavioral activation system (BAS), centered on the ventral striatum (VS), and its dopaminergic irrigation, activated by cues for reward. Similarly, according to Cloninger (1987), the disinhibitory temperament trait of NS reflects genetically determined variation in dopaminergically mediated BAS reactivity. When activated, the BAS can be characterized as an impulsive "go" system that activates on-going appetitive behavior (Pine et al., 2010).

Research is accumulating to suggest that variation in the DA synthesis pathway in particular plays a key role in the etiology of EXT. DA synthesis occurs within DA neurons. Tyrosine is transported into the cell via amino acid carriers in the bloodbrain barrier and cell membranes. Once in the intracellular space it is hydroxylated to $\mathrm{L}-3,4$-dihydroxiphenylalanine (L-DOPA) by tyrosine hydroxylase (TH). L-DOPA is then decarboxylated by aromatic L-amino acid decarboxylase [AADC; also known as dopa decarboxylase (DDC)] to DA (Elsworth and Roth, 2009). Variants [single nucleotide polymorphisms (SNPs)] in the DDC gene have been associated with nicotine (Ma et al., 2005; Yu et al., 2006; Zhang et al., 2006), alcohol (Agrawal et al., 2011; Kristjansson et al., 2012) and illicit drug (Hack et al., 2011) misuse, and most recently, disordered gambling (Lind et al., 2012). Importantly, Derringer et al. (2010) found that a combination of multiple SNPs in the DDC gene predicted individual variation in sensation seeking traits, suggesting that genetic variation in DA synthesis is related to broad EXT risk.

Positron Emission Tomography (PET) can be used to study the activity of AADC/DDC in pre-synaptic DA terminals in the living brain. The PET tracer 6- $\left[{ }^{18} \mathrm{~F}\right]$ fluoro-L-DOPA (FDOPA), a radioactive analog of $\mathrm{L}-\mathrm{DOPA}$, the precursor of DA, is taken up by pre-synaptic dopaminergic neurons and is metabolized by AADC/DDC to $18 \mathrm{~F}-\mathrm{DA}$, which is trapped and stored within vesicles in the nerve terminals (Kumakura and Cumming, 2009). FDOPA uptake, quantified as the influx constant $K_{\mathrm{I}}$, can be used as a measure of AADC/DDC activity and vesicular storage capacity (Brown et al., 1999). High values for FDOPA $K_{\mathrm{I}}$ are observed in areas of dense DA nerve terminal innervation, such as the striatum, and FDOPA has been extensively used to probe the functional integrity of striatal dopaminergic neurons in PD (Brooks, 2010) where uptake correlates with the number of surviving nigrostriatal cell numbers (Snow et al., 1993). Notably, FDOPA studies in non-PD populations have shown relatively increased striatal $K_{\mathrm{I}}$ values in alcohol (Tiihonen et al., 1998) and nicotine (Salokangas et al., 2000) dependent individuals, although those early studies did not measure disinhibitory personality traits, and could not resolve dorsal and ventral striatal regions. Further, Laakso et al. (2005) found increased striatal FDOPA uptake in A1+ allele carriers of the Taq1A polymorphism of the TTC12-ANKK1-DRD2 gene cluster, variation in which has been linked with EXT risk (Ducci et al., 2011).

Collectively, the research outlined above suggests that individual variation in DA synthesis capacity, particularly in the VS, underpins individual variation in trait disinhibition. Here, we tested the hypothesis that increased FDOPA uptake in VS, which is relatively spared in PD (Kish et al., 1988), would predict increased trait disinhibition or general EXT risk, in the context of PD.

\section{MATERIALS AND METHODS PATIENTS}

We studied 18 men with early-stage (symptom duration $<2$ years) idiopathic PD based on UK PD Society Brain Bank diagnostic criteria. Table 1 summarizes their clinical characteristics. Disease severity was rated with the Unified Parkinson's Disease Rating Scale (UPDRS) motor subscale while in an "off" condition withdrawn from medication before PET. Assessment of trait disinhibition, as well as PET scanning, was performed in a practically defined off state. Patients with pronounced tremor that would have produced difficulty with PET imaging, as well as patients with comorbid psychiatric or systemic physical illness were excluded. This cohort of 18 patients was drawn from a larger group of 186 PD patients that formed the multicentre REAL-PET investigation enrolled population. Drug escalation, tablet frequency, dose, and UPDRS motor response to medication have been described previously (Whone et al., 2003b). At the time of PET scanning, patients had only been started on dopaminergic medication within the

Table 1 | Patient characteristics.

\begin{tabular}{ll}
\hline & $\begin{array}{l}\text { Parkinson's disease } \\
\text { patients }(\boldsymbol{n}=\mathbf{1 8})\end{array}$ \\
\hline Gender (male/female) & $18 / 0$ \\
Age (years, mean \pm SD, range) & $64 \pm 7$, range 47-76 \\
UPDRS motor in "off" (mean \pm SD) & $14.6 \pm 6.5$ \\
GDS Depression (mean \pm SD) & $9.8 \pm 8.9$
\end{tabular}


previous 4-12 weeks, and were receiving low doses of either LDOPA (between $300 \mathrm{mg}$ to a maximum daily dose of $\sim 400 \mathrm{mg}$ at time of PET) or a DA agonist (between $3 \mathrm{mg}$ of ropinirole to a maximum daily dose of $\sim 8 \mathrm{mg}$ at time of PET). Patients were administered the 30-item Geriatric Depression Scale (GDS), validated for use in PD (Ertan et al., 2005).

The study was limited to men for several reasons. Firstly, ICDs and addictions in PD are more prevalent in males than females (Weintraub et al., 2010), as they are in non-PD populations (Eaton et al., 2012). Secondly, there are sex differences in DA synthesis capacity (Laakso et al., 2002). Thirdly, genetic factors for NS are excellent markers for EXT tendencies in males, but not females (Agrawal et al., 2004; Pitzer et al., 2007), although it is unclear whether this sex difference is an artifact of the manner in which males and females interpret the NS construct or whether there are true differences in the magnitude of genetic influence across males and females. It will be important in future studies to include females with PD.

Permission to undertake the study was granted by the Ethics Committee of Hammersmith, Queen Charlotte's \& Chelsea, and Acton Hospital Trust and all participants gave written informed consent following a full explanation of the procedure, in accordance with the declaration of Helsinki. The Administration of Radioactive Substances Advisory Committee (ARSAC) of the UK approved radioisotope use.

\section{MEASUREMENT OF TRAIT DISINHIBITION (VS. CONSTRAINT)}

Our measure of trait disinhibition (vs. constraint) was based on NS from Cloninger's Tri-dimensional Personality Questionnaire (TPQ; Cloninger, 1987). The version of the TPQ used here was a 100-item, self-administered, true-false instrument. The questionnaire is scored so that higher scores reflect greater NS.

As originally constructed (Cloninger, 1987) TPQ-NS comprised four narrow facet-level scales: Exploratory Excitability vs. Stoic Rigidity (NS1), Impulsiveness vs. Reflection (NS2), Extravagance vs. Reserve (NS3), and Disorderliness vs. Regimentation (NS4). When Ando et al. (2004), however, examined the genetic and environmental factor structure of NS, factor analysis of the genetic inter-correlations yielded factors that did not fully resemble the phenotypic structure of NS as proposed by Cloninger (1987). NS was revised (r-NS) to consist of Impulsiveness vs. Reflection (NS2), Extravagance vs. Reserve (NS3) and Disorderliness vs. Regimentation (NS4), excluding Exploratory Excitability vs. Stoic Rigidity (NS1). Further, Flory et al. (2006), using factor analysis in a large normative sample of middle-aged adults, found Impulsiveness vs. Reflection (NS2) and Extravagance vs. Reserve (NS3) to have high loadings on a "non-planning impulsivity" factor, together with the Barratt Impulsiveness Scale (BIS), whereas Exploratory Excitability vs. Stoic Rigidity (NS1) loaded on a distinct "Openness to Experience" factor, and Disorderliness vs. Regimentation (NS4) failed to load strongly on any single factor. Hence, in the current study, we focused on those r-NS facets most strongly linked to trait disinhibition: Impulsiveness (vs. Reflection; NS2; eight items) and Extravagance (vs. Reserve; NS3; seven items). Sample items include "I often react so strongly to unexpected news that I say or do things that I regret," "I often have to change my decisions because I had a wrong hunch or mistaken first impression"
(Impulsivity, NS2) and "I often spend money until I run out of cash or get into debt from using too much credit," "Because I so often spend too much money on impulse, it is hard for me to save money-even for special plans like a vacation" (Extravagance, NS3).

\section{PET SCANNING PROTOCOL}

Patients stopped medication at least $12 \mathrm{~h}$ prior to scanning. All participants underwent three-dimensional FDOPA PET using an ECAT EXACT HR++ (CTI/Siemens 966) camera, which covers an axial field of view of $23.4 \mathrm{~cm}$ and provides 95 transaxial planes. The tomograph has a spatial resolution of $4.8+0.2 \mathrm{~mm}$ FWHM (transaxial, $1 \mathrm{~cm}$ off axis) and $5.6+0.5 \mathrm{~mm}$ (axial, on axis) after image reconstruction (Spinks et al., 2000). A transmission scan, which corrects for attenuation of emitted radiation by skull and tissues, was acquired using a single rotating photon point source of $150 \mathrm{MBq}$ of ${ }^{137} \mathrm{Cs}$. Thirty seconds after the start of the emission scan, $110 \mathrm{MBq}$ of FDOPA in $10 \mathrm{ml}$ normal saline was infused intravenously over $30 \mathrm{~s}$. Three-dimensional sinograms of emission data were then acquired over $94 \mathrm{~min}$ as 26 time frames. Patients were placed in the scanner, orientated parallel to the orbito-metal line and head positioning was monitored throughout the scan.

\section{IMAGE QUANTIFICATION}

Parametric images of specific FDOPA uptake ( $\mathrm{K}_{\mathrm{I}}$ maps) were created at a voxel level for the whole brain using the Patlak graphical approach (Patlak and Blasberg, 1985) with a cerebellar cortex reference input function (Moore et al., 2003). Qualitative summated images created from the dynamic FDOPA time series by integrating all 26 frames of the dynamic image were also produced and then transformed into standard stereotaxic [Montreal Neurological Institute (MNI)] space using an FDOPA template created in-house from a healthy volunteer database. These so-called ADD images contain both tracer delivery and specific uptake information and provide adequate anatomical detail to allow stereotaxic manipulations. Subsequently, the $\mathrm{K}_{\mathrm{I}}$ maps were also individually normalized to MNI stereotaxic space by applying the transformation parameters defined during the normalization of their respective ADD image. This spatial transformation of parametric images made it possible to perform a region of interest (ROI) analysis as described below.

\section{REGION OF INTEREST ANALYSIS}

An ROI analysis was performed using a fixed object map template after stereotaxic transformation of all images into standard (MNI) space. This approach effectively normalizes brain position and shape and so avoids variability of regions due to head size and position and subjective free hand definition. Standard ROI object maps that outlined the left and right hemisphere VS, caudate, and putamen were defined on the MNI single-subject ROI in stereotaxic space (Moore et al., 2003, 2008). The standard object map was placed onto the transformed $\mathrm{K}_{\mathrm{I}}$ maps, and values for specific FDOPA uptake were obtained for each region (see Figure 1 for ROIs). When performing our ROI analysis a manual correction for head movement was employed as described previously (Whone et al., 2003a).

To limit the number of comparisons, and because of our specific a priori hypothesis, $K_{\mathrm{I}}$ values (units: $\mathrm{mlg}^{-1} \mathrm{~min}^{-1}$ ) for the 


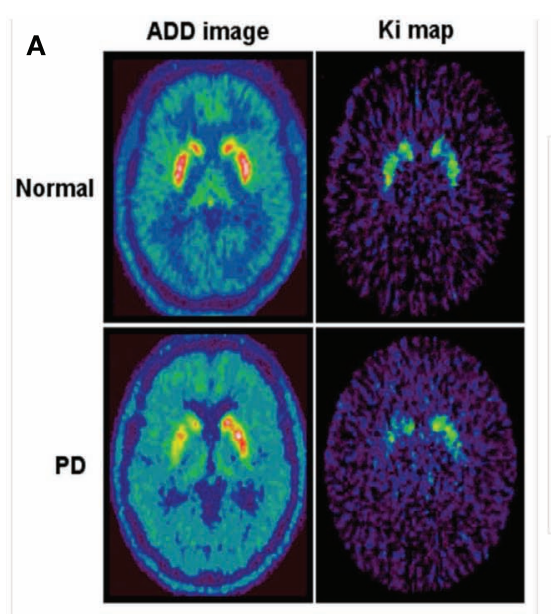

C MNI T1 MRI

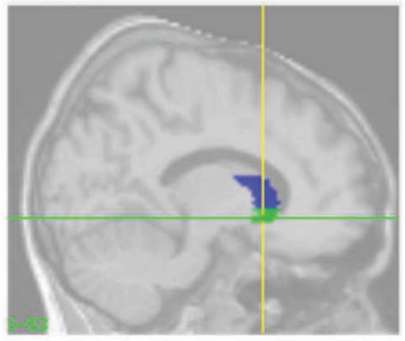

B

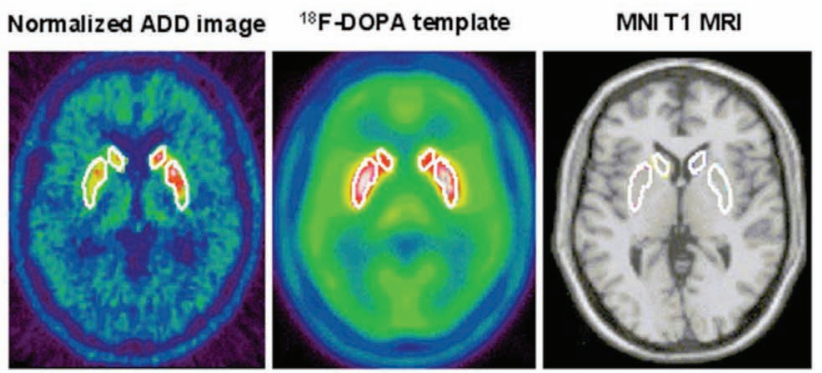

ROI's on Ki map - sagittal

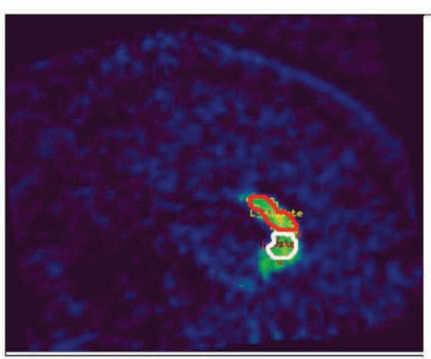

ROI's on Ki map - coronal

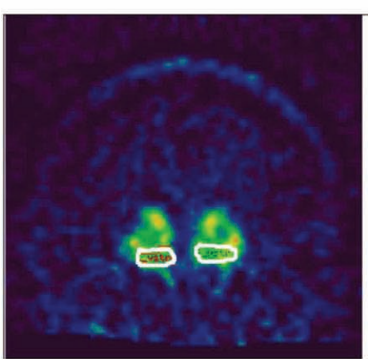

FIGURE 1 | The figure shows in (A) an FDOPA ADD (summed) and net influx rate constant $\left(K_{1}\right)$ image of a single slice from a healthy individual (top panels) and a patient with PD (bottom panels). In these images normalization to (MNI) space has been performed. Asymmetric decreased putamen and caudate uptake can be seen in the patient with PD. In (B) the figure shows; a template region object map overlying: the putamen and caudate nucleus bilaterally in a normalized FDOPA ADD image from a PD patient; the FDOPA template (created from five healthy controls) and the canonical single-subject T1 MRI found in SPM 99. (C) Shows the template object map, with volumes shaded, for the ventral striatum and caudate nucleus overlain on the canonical single-subject T1 MRI in sagittal section and next to it a spatially normalized $K_{1}$ image in sagittal section with the ventral striatum and caudate nucleus object map overlain. Also shown is a spatially normalized coronal section $K_{1}$ map through the ventral striatum with the object map overlain. caudate and putamen ROIs were averaged to form left and right dorsal striatum (DS) ROIs. Exploratory data analysis revealed that $K_{\mathrm{I}}$ and NS data were normally distributed, and so we examined the relation between them using Pearson's correlation coefficient. Statistical significance was set at $p<0.01$.

\section{RESULTS}

Mean \pm SD scores in our PD sample for NS2 (Impulsivity) and NS3 (Extravagance) were $3.1 \pm 1.6$ and $3.1 \pm 1.7$, respectively. Whilst population norms for individual NS facets are unavailable, the total NS score (NS1 + NS2 + NS3 + NS4) of the current PD sample $(13.6 \pm 4)$ was comparable to that published for agematched healthy male controls $(n>1000$; mean age $67 \pm 8$; total $\mathrm{NS}=11.6 \pm 5$; Stallings et al., 1996). Mean \pm SD FDOPA $K_{\mathrm{I}}$ values for left and right VS and left and right DS are reported in Table 2.

In line with our a priori hypothesis, we found a significant correlation between NS3 (Extravagance) scores and left VS FDOPA $K_{\mathrm{I}}$ values $[r(16)=0.61, p=0.008,95 \% \mathrm{CI} 0.20-0.83$; Figure 2]. This relationship was unchanged when controlling for both age and GDS depression scores $(r=0.63, p=0.009)$. There was a similar
Table 2 | FDOPA $K_{I}$ values in regions of interest.

$\begin{array}{ll}\text { Region } & \text { FDOPA } \kappa_{1} \text { values } \\ & (\text { mean } \pm \text { SD) }\end{array}$

Right ventral striatum

Left dorsal striatum

Right dorsal striatum
Left ventral striatum
$0.0127 \pm 0.0015$

$0.0120 \pm 0.0014$

$0.0115 \pm 0.0018$

$0.0108 \pm 0.0015$ trend in the right VS that failed to reach our pre-specified level of statistical significance $(r=0.53, p=0.026)$. (An additional analysis revealed that the slightly greater correlation between left VS FDOPA $K_{\mathrm{I}}$ and NS3 was not a result of asymmetry of Parkinsonian symptoms). Furthermore, neither left $(r=-0.13, p=0.60)$ nor right $(r=-0.22, p=0.38)$ VS FDOPA $K_{\mathrm{I}}$ values correlated with UPDRS motor scores. There was no significant relation between DS FDOPA $K_{I}$ values and NS3 scores, although the correlation with right DS values trended toward significance (left, $r=0.27, p=0.27$; right, $r=0.41, p=0.09$ ). Importantly, however, the correlation between left VS FDOPA $K_{\mathrm{I}}$ values and NS3 scores 


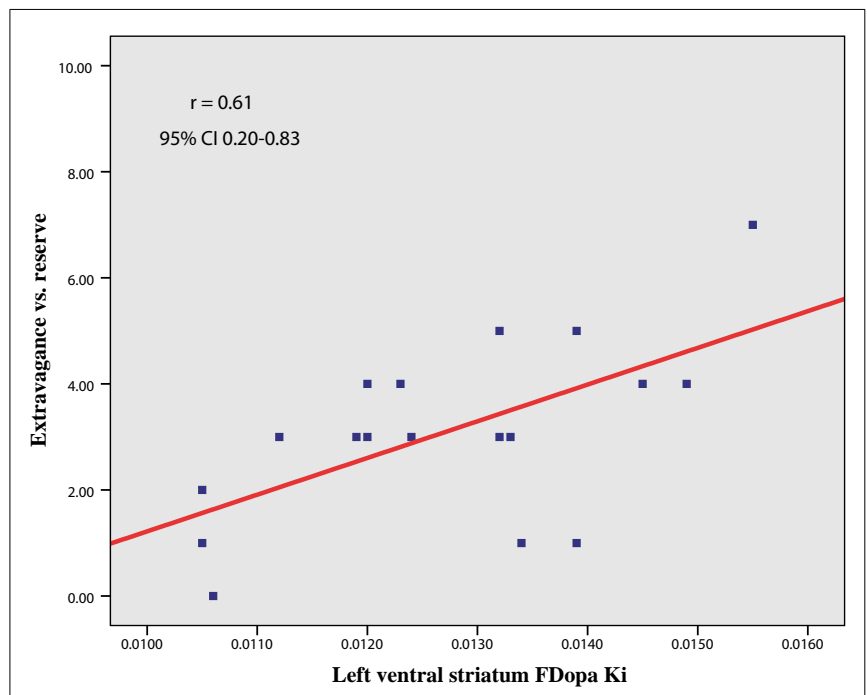

FIGURE 2 | Scatter plot (and line of best fit) showing the relation between trait disinhibition (NS3, Extravagance vs. reserve) and ventral striatal dopamine synthesis capacity (FDOPA $K_{1}$ ) in Parkinson's disease.

was significantly greater than that between either left $[t=2.59, p$ $(1$-tail $)=0.01]$ or right $[t=1.46, p(1$-tail $)=0.08]$ DS FDOPA $K_{\mathrm{I}}$ values and NS3 scores.

Against our hypothesis, however, there was no significant correlation between NS2 (Impulsivity) scores and VS FDOPA $K_{\mathrm{I}}$ values (left, $r=0.08, p=0.77$; right, $r=0.30, p=0.22$ ). Nor was there a significant correlation between NS2 scores and DS $K_{\mathrm{I}}$ values (left, $r=-0.12, p=0.65$; right, $r=0.22, p=0.37$ ). The

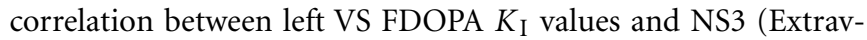
agance) scores was significantly greater than that between left VS FDOPA $K_{\mathrm{I}}$ values and NS2 (Impulsivity) scores $[t=2.67, p$ $(1$-tail $)=0.008]$.

\section{DISCUSSION}

Our findings provide new insights into the neurobiology of potential vulnerability to impulse control problems in PD. Consistent with our hypothesis, we found that variation in trait disinhibition (vs. constraint), a continuously varying endophenotype for EXT or impulse-control psychopathology, was associated with levels of DA synthesis capacity in the VS. Individuals with higher levels of trait disinhibition, in particular, tendencies to financial irresponsibility and extravagance, had greater DA synthesis capacity, as indexed by FDOPA $K_{\mathrm{I}}$ values in the left (and to a lesser extent, right) ventral, but not dorsal, striatum.

Although ICDs in PD have to date been treated as categorical (present/absent) disorders, it is now widely accepted that such disorders do not delineate highly discrete and easily distinguished categories. Rather, they delineate continuous, normally distributed underlying propensities to experience psychopathology, with personality traits linked to behavioral disinhibition forming the core of an EXT spectrum (Clark, 2005; Krueger et al., 2007). I.e., psychopathology represents the extremes of continuously distributed temperament traits. This general temperamental propensity to EXT, rather than its manifestations in particular disorders is therefore a key focus for etiological investigations.

Whilst a recent study linked genetic variation in DDC activity to an EXT endophenotype (sensation seeking) in healthy individuals (Derringer et al., 2010), and sensation seeking has been linked to increased ventral striatal BOLD-fMRI response during reward anticipation (Bjork et al., 2008; see also Yau et al., 2012), ours is the first demonstration that variation in trait disinhibition is linked to variation in DDC activity in the VS in PD, an important brain region underlying inter-individual variation in behavioral disinhibition in preclinical models (Dalley et al., 2011).

We found that only the r-NS subscale NS3 (Extravagance vs. Reserve) was related to ventral striatal DA synthesis capacity. There was no such relation with the NS2 subscale (Impulsivity vs. Reflection), despite the relatively high correlation between NS2 and NS3 $(r=0.45)$. Both subscales showed a similar range of variation in our PD sample, suggesting this is not the reason for a lack of correlation between NS2 scores and VS FDOPA $K_{\mathrm{I}}$ values. NS3 appears more trait-like (evidenced by much higher test-rest correlation) than NS2 (Takeuchi et al., 2011), and appears to index those traits (irresponsibility, inability to approach life planfully) most strongly linked to general EXT risk (Krueger and South, 2009). It is particularly notable that only NS3 correlates with impaired decision-making on the Iowa Gambling Task (Álvarez-Moya et al., 2011), which has been linked to increased VS FDOPA $K_{\text {I values }}$ (Schlagenhauf et al., 2012).

On first glance, our results appear inconsistent with an earlier study that failed to find a correlation between trait NS and VS FDOPA $K_{I}$ values in unmedicated male PD patients (Kaasinen et al., 2001). However, that study used the total NS score from the original NS scales described by Cloninger (1987), and it is now clear (Ando et al., 2004) that the genetic and environmental factor structure of NS does not resemble the phenotypic structure of NS as originally proposed, making interpretation of that previous null result difficult.

FDOPA is not a specific ligand for DA neurons but rather is trapped by all neurons that contain DDC (Brown et al., 1999). Hence, it is a marker for all tissues that take up and store monoamines, including serotonin $(5-\mathrm{HT})$ as well as DA neurons (Tison et al., 1991). 5-HT has also been implicated in various aspects of impulsivity (Winstanley et al., 2005; Miyazaki et al., 2011). However, post hoc analysis of a midbrain raphe ROI (Moore et al., 2008), a structure in which FDOPA is a validated marker of serotonergic function in PD (Pavese et al., 2012), in our sample, found no significant correlation between FDOPA $K_{\mathrm{I}}$ values in the raphe and either NS2 (Impulsivity) or NS3 (Extravagance) scores $(r=0.11, p=0.67$ and $r=0.32$, $p=0.2$, respectively). Further, in MPTP treated monkeys, Karimi et al. (2013) found a near perfect correlation $\left(n=16, r^{2}=0.95\right)$ between striatal FDOPA $K_{\mathrm{I}}$ values obtained in vivo with PET and post-mortem striatal DA levels (measured using high performance liquid chromatography with electrochemical detection). It is likely, therefore, that individual differences in trait disinhibition are primarily related to individual differences in DA synthesis capacity.

This interpretation is consistent with several other recent findings on the neurobiology of impulse-control and addiction 
vulnerability. D2 autoreceptors located on DA nerve terminals exert a negative feedback regulation that reduces DA synthesis, DA neuron firing, and DA release (Wolf and Roth, 1990; Zhu et al., 1992). Bello et al. (2011) generated mice deficient in such D2 autoreceptors. These "autoDrd2KO" mice displayed elevated striatal DA synthesis and strikingly, demonstrated increased sensitivity to the rewarding and psychomotor stimulant properties of cocaine, together with a greatly exaggerated motivation to work for food reward. I.e., heightened DA synthesis in the autoDrd $2 \mathrm{KO}$ mice resulted in an addiction-prone, disinhibited phenotype. In humans, striatal DA synthesis capacity measured with $\left[\beta-{ }^{11} \mathrm{C}\right] \mathrm{DOPA}$ PET is negatively correlated with striatal D2 receptor density measured with $\left[{ }^{11} \mathrm{C}\right]$ raclopride PET (Ito et al., 2011). Given that many presynaptic D2 receptors in the striatum are DA autoreceptors (Sesack et al., 1994), increased DA synthesis capacity in humans may similarly reflect reduced D2 autoreceptor function. Notably, in animal models, variation in trait impulsivity, measured by premature responding on a 5-choice serial reaction time test of visual attention, has been linked to relatively reduced D2 receptor levels in the VS, functioning as autoreceptors (Besson et al., 2010).

Consistent with this, in humans, Buckholtz et al. (2010) (see also Zald et al., 2008) recently found that trait non-planning impulsivity was inversely correlated with D2/D3 autoreceptor availability in the substantia nigra/ventral tegmental area, measured using $[18 \mathrm{~F}]$ fallypride PET. Furthermore, Van Leare et al. (2009) found a selective negative correlation between cannabinoid CB1 receptor density, measured using [18F]MK-9470 PET, in left hemisphere limbic regions and NS3 (Extravagance) scores in healthy volunteers. Since CB1 receptor activation causes inhibition of DA synthesis (Moranta et al., 2004), reduced density of CB1 receptors would presumably result in higher levels of DA synthesis, and the negative correlation between CB1 receptor density and NS3 is consistent with the positive correlation between ventral striatal DA synthesis capacity and NS3 seen here.

Furthermore, Bello et al. (2011) found that autoDrd2KO mice showed exaggerated phasic DA release, resulting from a larger releasable pool of DA generated by the lack of DA synthesis inhibition in DA terminals. Similarly, in both monkeys (Doudet and Holden, 2003) and human individuals with PD (Piccini et al., 2003), the magnitude of amphetamine-induced striatal DA release as measured by [11C]-raclopride PET (an indirect measure of phasic DA release, Grace, 2008), is positively correlated with DA synthesis capacity measured using FDOPA PET. In humans, Buckholtz et al. (2010) found that trait disinhibition predicted greater amph-induced DA release (together with stronger drug-primed wanting) and the relation between midbrain autoreceptor availability and trait impulsivity was mediated via this enhanced amphetamine-induced striatal DA release.

The influence of variation in DA synthesis capacity on EXT tendency might result from DA's established role in reward processing, particularly the attribution of incentive salience (Berridge, 2007). Incentive salience is a motivational component of reward, one that transforms sensory information about rewards and reward cues into attractive, "wanted" incentives, motivating pursuit (Berridge, 2007). Notably, in animals, there is considerable individual variability in incentive salience attribution, and rats with a strong propensity to attribute incentive salience to reward cues also show heightened behavioral disinhibition, risk-taking, and an increased tendency to seek drugs like cocaine (Flagel et al., 2010). Available data suggest that animals prone to attribute incentive salience to reward cues have a more active DA system than those who do not (Marinelli and White, 2000; Tomie et al., 2000). In healthy volun-

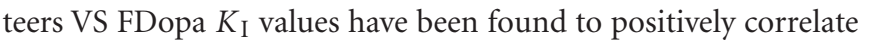
with BOLD-fMRI activity to reward cues in brain regions linked to incentive salience attribution (Siessmeier et al., 2006), and ventral striatal BOLD-fMRI response to reward cues in humans is increased as a function of trait non-planning impulsivity and is linked to genetic variation in the D2 (auto)-receptor (Forbes et al., 2009).

Of particular relevance to the development of extreme impulse control problems following treatment with dopaminergic medication in $\mathrm{PD}$, rats with heightened incentive salience attribution show a greater propensity for dopaminergic drug-induced sensitization - a form of neuroplasticity hypothesized to play a key role in addiction (Flagel et al., 2008). In particular, the incentive-sensitization theory (Robinson and Berridge, 2008) posits that excessive drug use arises from the excessive attribution of incentive salience to drug rewards and their cues, due to progressive neuroadaptations in DA projections to ventral striatal motivation circuitry. Strikingly, PD individuals with DA dysregulation syndrome were shown to exhibit potentiated L-DOPA-induced ventral striatal DA release, which correlated with exaggerated drug-primed L-DOPA wanting, together with enhanced responding to monetary reward (Evans et al., 2006). Also, PD (and non-PD) individuals with disordered gambling showed impaired DA D2 autoreceptor activity (Ray et al., 2012) and exaggerated VS DA release to gambling and other reward cues (O'Sullivan et al., 2011; see also Steeves et al., 2009; Joutsa et al., 2012a), consistent with incentivesensitization.

It is possible that, rather than reflecting an underlying neurobiological risk factor for ICDs in PD, increased VS FDOPA uptake could be the result of disease-related and/or drug-induced neuroplastic changes leading to disease- and/or drug-induced disinhibition. In the current sample of early-stage PD patients, who had only recently begun DA replacement therapy, however, mean ventral striatal FDOPA $K_{\mathrm{I}}$ values were very similar to those of healthy controls (Whone et al., 2004) and were unrelated to severity of PD. In animal models, there is some evidence that repeated treatments with DA agonist drugs can enhance basal DA synthesis in the VS (Rowlett et al., 1997) and frontal cortex (Chernoloz et al., 2012). However, other studies show persistent inhibition of DA synthesis following repeated treatment with DA agonists (Imperato et al., 1996). A study of detoxified alcoholics found no differences in VS DA synthesis capacity measured with FDOPA PET (Heinz et al., 2005). Very recently, Joutsa et al. (2012b) found increased medial orbitofrontal, but not ventral striatal, FDOPA uptake in 10 individuals with manifest ICDs in PD. Since disinhibitory traits were not measured in the patients or controls of that study, however, it may be that several of the controls had 
high EXT risk, explaining the lack of difference in VS FDOPA uptake between ICD cases and controls. Frontal, but not striatal, DA synthesis is also increased following stress (Reinhard et al., 1982), suggesting that enhanced frontal, but not ventral striatal, FDOPA uptake in ICD cases may reflect state, as opposed to trait, effects.

Furthermore, Giladi et al. (2007) and Bastiaens et al. (2013) found that the appearance of heightened impulse control problems in affected PD individuals began only after a median interval of $\sim 2$ years of treatment, and our patients had only recently been started on dopaminergic medication, within the previous 4-12 weeks, and were on only low doses of either L-DOPA or DA agonist. In addition, Voon et al. (2007) found that NS scores were not influenced by dopaminergic therapy. Importantly, numerous studies have found a shared genetic diathesis to underlie associations between EXT disorders and traits related to disinhibition, including NS (Young et al., 2000; Agrawal et al., 2004). Most critically, Derringer et al. (2010) found that genetic variation in DDC activity predicted variation in trait disinhibition, suggesting that variation in DDC activity reflects a trait EXT vulnerability, rather than a disease or medication-related effect (see also Engeln et al., 2012). Likewise, Flagel et al. (2010), found that, in rats, variation in incentive salience attribution and behavioral disinhibition are genetically influenced, correlated traits that depend on ventral striatal DA for their expression (Saunders and Robinson, 2012).

Hence, we think it highly unlikely that our findings of a positive correlation between levels of self-reported disinhibition and

\section{REFERENCES}

Agrawal, A., Jacobson, K. C., Prescott, C. A., and Kendler, K. S. (2004). A twin study of personality and illicit drug use and abuse/dependence. Twin Res. 7, 72-81.

Agrawal, A., Lynskey, M. T., Todorov,

A. A., Schrage, A. J., Littlefield,

A. K., Grant, J. D., et al. (2011).

A candidate gene association study

of alcohol consumption in young women. Alcohol Clin. Exp. Res. 35, $1-9$.

Álvarez-Moya, E. M., Ochoa, C., Jiménez-Murcia, S., Aymamí, M. N., Gómez-Peña, M., FernándezAranda, F., et al. (2011). Effect of executive functioning, decisionmaking and self-reported impulsivity on the treatment outcome of pathologic gambling. J. Psychiatry Neurosci. 36, 165-175.

Ando, J., Suzuki, A., Yamagata, S., Kijima, N., Maekawa, H., Ono, Y., et al. (2004). Genetic and environmental structure of Cloninger's temperament and character dimensions. J. Pers. Disord. 18, 379-393.

Bastiaens, J., Dorfman, B. J., Christos, B. J., and Nirenberg, M. J. (2013). Prospective cohort study of impulse control disorders in
Parkinson's disease. Mov. Disord. doi: 10.1002/mds.25291. [Epub

Bello, E. P., Mateo, Y., Gelman, D. M., Noaín, D., Shin, J. H., Low, M. J., et al. (2011). Cocaine supersensitivity and enhanced motivation for reward in mice lacking dopamine D2 autoreceptors. Nat. Neurosci. 14, 1033-1038.

Berridge, K. C. (2007). The debate over dopamine's role in reward: the case for incentive salience. Psychopharmacology (Berl.) 191, 391-431.

Besson, M., Belin, D., McNamara, R., Theobold, D. E. H., Castel, A., Beckett, V. L., et al. (2010). Dissociable control of impulsivity in rats by dopamine D2/3 receptors in the core and shell subregions of the nucleus accumbens. Neuropsychopharmacology 35, 560-569.

Bienfait, K. L., Menza, M., Mark, M. H., and Dobkin, R. D. (2010). Impulsive smoking in a patient with Parkinson's disease treated with dopamine agonists. J. Clin. Neurosci. 17, 539-540. mer, D. W. (2008). Incentive-elicited striatal activation in adolescent children of alcoholics. Addiction 103, 1308-1319. ahead of print].

Bjork, J. M., Knutson, B., and Hom-
VS DA synthesis capacity are a result of PD and its treatment with dopaminergic medication. Rather, we think they reflect genetically influenced, pre-existing neurobiological individual differences in VS DA synthesis capacity in PD patients, underpinning variation in trait disinhibition or EXT propensity, which in turn is associated with future ICD morbidity risk (as PD advances and dopaminergic drug therapy increases), resulting from an increased susceptibility to DAergic-drug-induced incentive-sensitization (Boileau et al., 2006). Longitudinal studies will be required to establish the validity of this account.

In conclusion, we have shown that temperamental vulnerability to impulse control or EXT problems such as disordered gambling in male PD patients is related to relatively greater DA synthesis capacity in the ventral, but not dorsal, striatum. Our results are consistent with preclinical models of EXT risk, and may prove informative in understanding the psychological and neurobiological mechanisms whereby individual differences in temperament contribute to the development of impulse control and addictive pathologies in the context of the treatment of PD and other neurological disorders.

\section{ACKNOWLEDGMENTS}

Support for this work was provided by Parkinson's UK (grant ref. G0603). We are most grateful to the technical PET staff for their assistance, to Dr N. Pavese for assistance with Figure 1 and to all the patients who participated in this study.
Blanco, C., Myers, J., and Kendler, K. S. (2012). Gambling, disordered gambling and their association with major depression and substance abuse: a web-based cohort and twin-sibling study. Psychol. Med. 42, 497-508.

Boileau, I., Dagher, A., Leyton, M., Gunn, R. N., Baker, G. B., Diksic, M., et al. (2006). Modelling sensitization to stimulants in humans: an [11C]raclopride/position emission tomography study in healthy men. Arch. Gen. Psychiatry 63, 1386-1395.

Brooks, D. J. (2010). Imaging approaches to Parkinson's disease. J. Nucl. Med. 51, 596-609.

Brown, W. D., Taylor, M. D., Roberts, A. D., Oakes, T. R., Schueller, M. J., Holden, J. E., et al. (1999). FluoroDOPA PET shows the nondopaminergic as well as dopaminergic destinations of levodopa. Neurology 53, 1212-1218.

Buckholtz, J. W., Treadway, M. T., Cowan, R. L., Woodward, N. D., Li, R., Ansari, M. S., et al. (2010). Dopaminergic network differences in human impulsivity. Science 329, 532.

Chernoloz, O., El Mansari, M., and Blier, P. (2012). Long-term administration of the dopamine D3/2 receptor agonist pramipexole increases dopamine and serotonin neurotransmission in the male rat forebrain. J. Psychiatry Neurosci. 37, 113-121.

Clark, L. A. (2005). Temperament as a unifying basis for personality and psychopathology. J. Abnorm. Psychol. 114, 505-521.

Cloninger, C. R. (1987). A systematic method for clinical description and classification of personality variants. Arch. Gen. Psychiatry 44, 573-588.

Dagher, A., and Robbins, T. W. (2009). Personality, addiction, dopamine: insights from Parkinson's disease. Neuron 61, 502-510.

Dalley, J. W., Everitt, B. J., and Robbins, T. W. (2011). Impulsivity, compulsivity, and top-down cognitive control. Neuron 69, 680-694.

Derringer, J., Krueger, R. F., Dick, D. M., Saccone, S., Grucza, R. A., Agrawal, A., et al. (2010). Predicting sensation seeking from dopamine genes: a candidatesystem approach. Psychol. Sci. 21, 1282-1290.

Doudet, D. J., and Holden, J. E. (2003). Raclopride studies of dopamine release: dependence on presynaptic integrity. Biol. Psychiatry 54, 1193-1199. 
Ducci, F., Kaakinen, M., Pouta, A., Hartikainen, A.-L., Veijola, J., Isohanni, M., et al. (2011). TTC12-ANKK1DRD2 and CHRNA5-CHRNA3CHRNB4 influence different pathways leading to smoking behavior from adolescence to mid-adulthood. Biol. Psychiatry 69, 650-660.

Eaton, N. R., Keyes, K. M., Krueger, R. F., Balsis, S., Skodol, A. E., Markon, K. E., et al. (2012). An invariant dimensional liability model of gender differences in mental disorder prevalence: evidence from a national sample. J. Abnorm. Psychol. 121, 282-288.

Elsworth, J. D., and Roth, R. H. (2009). "Dopamine," in Encyclopaedia of Neuroscience, ed. L. R. Squire (Amsterdam: Elsevier), 539-547.

Engeln, M., Ahmed, S., Vouillac, C., Tison, F., Bezard, E., and Fernagut, P.-O. (2012). Reinforcing properties of pramipexole in normal and parkinsonian rats. Neurobiol. Dis. 49C, 79-86.

Ertan, F. S., Ertan, T., Kiziltan, G., and Uyguçgil, H. (2005). Reliability and validity of the geriatric depression scale in depression in Parkinson's disease. J. Neurol. Neurosurg. Psychiatry 76, 1445-1447.

Evans, A. H., Lawrence, A. D., Potts, J., Appel, S., and Lees, A. J. (2005). Factors influencing susceptibility to compulsive dopaminergic drug use in Parkinson disease. Neurology 65, 1570-1574.

Evans, A. H., Pavese, N., Lawrence, A. D., Tai, Y. F., Appel, S., Doder, M., et al. (2006). Compulsive drug use linked to sensitized ventral striatal dopamine transmission. Ann. Neurol. 59, 852-858.

Flagel, S. B., Robinson, T. E., Clark, J. J., Clinton, S. M., Watson, S. J., Seeman, P., et al. (2010). An animal model of genetic vulnerability to behavioral disinhibition and responsiveness to reward-related cues: implications for addiction. Neuropsychopharmacology 35, 388-400.

Flagel, S. B., Watson, S. J., Akil, H., and Robinson, T. E. (2008). Individual differences in the attribution of incentive salience to a rewardrelated cue: influence on cocaine sensitization. Behav. Brain Res. 186, 48-56.

Flory, J. D., Harvey, P. D., Mitropoulou, V., New, A. S., Silverman, J. M., Siever, L., et al. (2006). Dispositional impulsivity in normal and abnormal samples. J. Psychiatr. Res. 40, 438-447.

Forbes, E. E., Brown, S. M., Kimak, M., Ferrell, R. E., Manuck, S. B., and
Hariri, A. R. (2009). Genetic variation in components of dopamine neurotransmission impacts ventral striatal reactivity associated with impulsivity. Mol. Psychiatry 14, 60-70.

Forbush, K. T., and Watson, D. (2013). The structure of common and uncommon mental disorders. Psychol. Med. 43, 97-108.

Gallagher, D. A., O'Sullivan, S. S., Evans, A. H., Lees, A. J., and Schrag, A. (2007). Pathological gambling in Parkinson's disease: risk factors and differences from dopamine dysregulation. An analysis of published case series. Mov. Disord. 22, 1757-1763.

Giladi, N., Weitzman, N., Schreiber, S., Shabtai, H., and Peretz, C. (2007). New onset heightened interest or drive for gambling, shopping, eating or sexual activity in patients with Parkinson's disease: the role of dopamine agonist treatment and age at motor symptoms onset. $J$. Psychopharmacol. 21, 501-506.

Grace, A. A. (2008). Physiology of the normal and dopamine-depleted basal ganglia: insights into levodopa pharmacotherapy. Mov. Disord. 23, S560-S569.

Hack, L. M., Kalsi, G., Aliev, F., Kuo, P. H., Prescott, C. A., Patterson, D. G., et al. (2011). Limited associations of dopamine system genes with alcohol dependence and related traits in the Irish Affected Sib Pair Study of Alcohol Dependence (IASPSAD). Alcohol. Clin. Exp. Res. 35, 376-385.

Heinz, A., Siessmeier, T., Wrase, J., Buchholz, H. G., Gründer, G., Kumakura, Y., et al. (2005). Correlation of alcohol craving with striatal dopamine synthesis capacity and D2/3 receptor availability: a combined [18F]DOPA and [18F]DMFP PET study in detoxified alcoholic patients. Am. J. Psychiatry 162, 1515-1520.

Imperato, A., Obinu, M. C., Carta, G., Mascia, M. S., Casu, M. A., and Gessa, G. L. (1996). Reduction of dopamine release and synthesis by repeated amphetamine treatment: role in behavioral sensitization. Eur. J. Pharmacol. 317, 231-237.

Ito, H., Kodaka, F., Takahashi, H., Takano, H., Arakawa, R., Shimada, H., et al. (2011). Relation between presynaptic and postsynaptic dopaminergic functions measured by positron emission tomography: implications of dopaminergic tone. J. Neurosci. 31, 7886-7890.

Joutsa, J., Johansson, J., Niemelä, S., Ollikainen, A., Hirvonen, M. M., Piepponen, P., et al. (2012a). Mesolimbic dopamine release is linked to symptom severity in pathological gambling. Neuroimage 60, 1992-1999.

Joutsa, J., Martikainen, K., Niemelä, S., Johansson, J., Forsback, S., Rinne, J. O., et al. (2012b). Increased medial orbitofrontal [18F]fluorodopa uptake in parkinsonian impulse control disorders. Mov. Disord. 27, 778-782.

Kaasinen, V., Nurmi, E., Bergman, J., Eskola, O., Solin, O., Sonninen, P., et al. (2001). Personality traits and brain dopaminergic function in Parkinson's disease. Proc. Natl. Acad. Sci. U.S.A. 98, 13272-13277.

Karimi, M., Tian, L., Brown, C. A., Flores, H. P., Loftin, S. K., Videen, T. O., et al. (2013). Validation of nigrostriatal PET measures: critical limits. Ann. Neurol. doi:10.1002/ana.23798. [Epub ahead of print].

Kessler, R. C., Hwang, I., LaBrie, R., Petukhova, M., Sampson, N. A., Winters, K. C., et al. (2008). DSMIV pathological gambling in the national comorbidity survey replication. Psychol. Med. 38, 1351-1360.

Khan, A. A., Jacobson, K. C., Gardner, C. O., Prescott, C. A., and Kendler, K. S. (2005). Personality and comorbidity of common psychiatric disorders. Br. J. Psychiatry 186, 190-196.

Kish, S. J., Shannak, K., and Hornykiewicz, O. (1988). Uneven pattern of dopamine loss in the striatum of patients with idiopathic Parkinson's disease: pathophysiologic and clinical implications. $N$. Engl. J. Med. 318, 876-880.

Kristjansson, S. D., Agrawal, A., LessovSchlaggar, C. N., Madden, P. A. Cooper, M. L., Bucholz, K. K., et al. (2012). The relationship between rs3779084 in the dopa decarboxylase (DDC) gene and alcohol consumption is mediated by drinking motives in regular smokers. Alcohol. Clin. Exp. Res. 36, 162-170.

Krueger, R. F., Markon, K. E., Patrick, C. J., Benning, S. D., and Kramer, M. D. (2007). Linking antisocial behavior, substance use, and personality: an integrative quantitative model of the adult externalizing spectrum. $J$. Abnorm. Psychol. 116, 645-666.

Krueger, R. F., and South, S. C. (2009). Externalizing disorders: cluster 5 of the proposed meta-structure for DSM-V and ICD-11. Psychol. Med. 39, 2061-2070.

Kumakura, Y., and Cumming, P. (2009). PET studies of cerebral levodopa metabolism: a review of clinical findings and modelling approaches. Neuroscientist 15, 635-650.

Laakso, A., Pohjalainen, T., Bergman, J., Kajander, J., Haaparanta, M., Solin,
O., et al. (2005). The A1 allele of the human D2 dopamine receptor gene is associated with increased activity of striatal L-amino acid decarboxylase in healthy subjects. Pharmacogenetics 15, 387-391.

Laakso, A., Vilkman, H., Bergman, J., Haaparanta, M., Solin, O., Syvälahti, E., et al. (2002). Sex differences in striatal presynaptic dopamine synthesis capacity in healthy subjects. Biol. Psychiatry 52, 759-763.

Lawrence, A. D., Evans, A. H., and Lees, A. J. (2003). Compulsive use of dopamine replacement therapy in Parkinson's disease: reward systems gone awry? Lancet Neurol. 2, 595-604.

Lind, P. A., Zhu, G., Montgomery, G. W., Madden, P. A., Heath, A. C., Martin, N. G., et al. (2012). Genomewide association study of a quantitative disordered gambling trait Addict. Biol. doi: 10.1111/j.13691600.2012.00463.x. [Epub ahead of print].

Ma, J. Z., Beuten, J., Payne, T. J., Dupont, R. T., Elston, R. C., and Li, M. D. (2005). Haplotype analysis indicates an association between the DOPA decarboxylase (DDC) gene and nicotine dependence. Hum. Mol. Genet. 14, 1691-1698.

MacLaren, V. V., Fugelsang, J. A., Harrigan, K. A., and Dixon, M. J. (2011). The personality of pathological gamblers: a metaanalysis. Clin. Psychol. Rev. 31, 1057-1067.

Marinelli, M., and White, F. J. (2000). Enhanced vulnerability to cocaine self-administration is associated with elevated impulse activity of midbrain dopamine neurons. $J$. Neurosci. 20, 8876-8885.

Markon, K. E., Krueger, R. F., and Watson, D. (2005). Delineating the structure of normal and abnormal personality: an integrative hierarchical approach. J. Pers. Soc. Psychol. 88, 139-157.

Miyazaki, K., Miyazaki, K. W., and Doya, K. (2011). Activation of dorsal raphe serotonin neurons underlies waiting for delayed rewards. J. Neurosci. 31, 469-479.

Moore, R. Y., Whone, A. L., and Brooks, D. J. (2008). Extrastriatal monoamine neuron function in Parkinson's disease: an 18Fdopa PET study. Neurobiol. Dis. 29, 381-390.

Moore, R. Y., Whone, A. L., McGowan, S., and Brooks, D. J. (2003). Monoamine neuron innervation of the normal human brain: an 18FDOPA PET study. Brain Res. 982, 137-145. 
Moranta, D., Esteban, S., and GarcíaSevilla, J. A. (2004). Differential effects of acute cannabinoid drug treatment, mediated by $\mathrm{CB} 1$ receptors, on the in vivo activity of tyrosine and tryptophan hydroxylase in the rat brain. Naunyn Schmiedebergs Arch. Pharmacol. 369, 516-524.

Oleski, J., Cox, B. J., Clara, I., and Hills, A. (2011). Pathological gambling and the structure of common mental disorders. J. Nerv. Ment. Dis. 199, 956-960.

O'Sullivan, S., Djamshidian, A., Ahmed, Z., Evans, A. H., Lawrence, A. D., Holton, J. L., et al. (2010). Impulsivecompulsive spectrum behaviours in pathologically confirmed progressive supranuclear palsy. Mov. Disord. 25, 638-642.

O’Sullivan, S. S., Wu, K., Politis, M., Lawrence, A. D., Evans, A. H., Bose, S. K., et al. (2011). Cue-induced striatal dopamine release in Parkinson's disease associated impulse control disorders. Brain 134, 969-978.

Patlak, C. S., and Blasberg, R. G. (1985). Graphical evaluation of blood-to-brain transfer constants from multiple-time uptake data. Generalizations. J. Cereb. Blood Flow Metab. 5, 584-590.

Pavese, N., Simpson, B. S., Metta, V., Ramlackhansingh, A., Chaudhuri, K. R., and Brooks, D. J. (2012). [(18)F]FDOPA uptake in the raphe nuclei complex reflects serotonin transporter availability. A combined [(18F)]FDOPA and [(11)C]DASB PET study in Parkinson's disease. Neuroimage 59, 1080-1084.

Piccini, P., Pavese, N., and Brooks, D. J. (2003). Endogenous dopamine release after pharmacological challenge in Parkinson's disease. Ann. Neurol. 53, 647-653.

Pickering, A. D., and Gray, J. A. (1999). "The neuroscience of personality," in Handbook of Personality: Theory and Research, 2nd Edn, eds L. A. Pervin and O. P. John (New York: The Guilford Press), 277-299.

Pine, A., Shiner, T., Seymour, B., and Dolan, R. J. (2010). Dopamine, time and impulsivity in humans. $\mathrm{J}$. $\mathrm{Neu}$ rosci. 30, 8888-8896.

Pitzer, M., Esser, G., Schmidt, M. H., and Laucht, M. (2007). Temperament in the developmental course: a longitudinal comparison of New York longitudinal study-derived dimensions with the junior temperament and character inventory. Compr. Psychiatry 48, 572-582.

Ray, N., Miyasaki, J. M., Zurowski, M., Ko, J. H., Cho, S. S., Lang, A. E., et al. (2012). Extrastriatal dopaminergic abnormalities of DA homeostasis in Parkinson's patients with medication-induced pathological gambling: a [11C] FLB-457 and PET study. Neurobiol. Dis. 48, 519-525.

Reinhard, J. F. Jr., Bannon, M. J., and Roth, R. H. (1982). Acceleration by stress of dopamine synthesis and metabolism in prefrontal cortex: antagonism by diazepam. Naunyn Schmiedebergs Arch. Pharmacol. 318, 374-377.

Robinson, T. E., and Berridge, K. C. (2008). The incentive sensitization theory of addiction: some current issues. Philos. Trans. R. Soc. Lond. B. Biol. Sci. 363, 3137-3146.

Rowlett, J. K., Mattingly, B. A., and Bardo, M. T. (1997). Locomotor activity and dopamine synthesis following 1 and 15 days of withdrawal from repeated apomorphine treatments. Pharmacol. Biochem. Behav. 57, 13-18.

Salokangas, R. K., Vilkman, H., Ilonen, T., Taiminen, T., Bergman, J., Haaparanta, M., et al. (2000). High levels of dopamine activity in the basal ganglia of cigarette smokers. Am. J. Psychiatry 157, 632-634.

Saunders, B. T., and Robinson, T. E. (2012). The role of dopamine in the accumbens core in the expression of pavlovian-conditioned responses. Eur. J. Neurosci. 36, 2521-2532.

Schlagenhauf, F., Rapp, M. A., Huys, Q. J., Beck, A., Wüstenberg, T., Deserno, L., et al. (2012). Ventral striatal prediction error signaling is associated with dopamine synthesis capacity and fluid intelligence. Hum. Brain. Mapp. doi: 10.1002/hbm.22000. [Epub ahead of print].

Sesack, S. R., Aoki, C., and Pickel, V. M. (1994). Ultrastructural localization of D2 receptor-like immunoreactivity in midbrain dopamine neurons and their striatal targets. J. Neurosci. 14, 88-106.

Sher, K. J., Bartholow, B. D., and Wood, M. D. (2000). Personality and substance use disorders: a prospective study. J. Consult. Clin. Psychol. 68, 818-829.

Sher, K. J., and Trull, T. J. (1994). Personality and disinhibitory psychopathology: alcoholism and antisocial personality disorder. $J$. Abnorm. Psychol. 103, 92-102.

Siessmeier, T., Kienast, T., Wrase, J., Larsen, J. L., Braus, D. F., Smolka, M. N., et al. (2006). Net influx of plasma 6-[18F]fluoro-L-DOPA (FDOPA) to the ventral striatum correlates with prefrontal processing of affective stimuli. Eur. J. Neurosci. 24, 305-313.
Slutske, W. S., Cho, S. B., Piasecki, T. M. and Martin, N. G. (2013). Genetic overlap between personality and risk for disordered gambling: evidence from a national community-based Australian twin study. J. Abnorm. Psychol. 122, 50-55.

Slutske, W. S., Moffitt, T. E., Poulton, R., and Caspi, A. (2012). Undercontrolled temperament at age 3 predicts disordered gambling at age 32: a longitudinal study of a complete birth cohort. Psychol. Sci. 23, 510-516.

Snow, B. J., Tooyama, I., McGeer E. G., Yamada, T., Calne, D B., Takahashi, H., et al. (1993). Human positron emission tomographic [18F]fluorodopa studies correlate with dopamine cell counts and levels. Ann. Neurol. 34, 324-330.

Spinks, T. J., Jones, T., Bloomfield, P. M. Bailey, D. L., Miller, M., Hogg, D. et al. (2000). Physical characteristics of the ECAT EXACT 3D positron tomograph. Phys. Med. Biol. 45, 2601-2261.

Stallings, M. C., Hewitt, J. K., Cloninger, C. R., Heath, A. C., and Eaves, L. J. (1996). Genetic and environmental structure of the tridimensional personality questionnaire: three or four temperament dimensions? J. Pers. Soc. Psychol. 70, 127-140.

Steeves, T. D. L., Miyasaki, J., Zurowski, M., Lang, A. E., Pellecchia, G., Van Eimeren, T., et al. (2009). Increased striatal dopamine release in Parkinsonian patients with pathological gambling: a [11C] raclopride PET study. Brain 132, 1376-1385.

Takeuchi, M., Miyaoka, H., Tomoda, A., Suzuki, M., Lu, X., and Kitamura, T. (2011). Validity and reliability of the Japanese version of the temperament and character inventory: a study of university and college students. Compr. Psychiatry 52, 109-117.

Tiihonen, J., Vilkman, H., Rasanen, P., Ryynanen, O.-P., Hakko, H. Bergman, J., et al. (1998). Striatal presynaptic dopamine function in type 1 alcoholics measured with positron emission tomography. $\mathrm{Mol}$. Psychiatry 4, 156-161.

Tison, F., Normand, E., Jaber, M. Aubert, I., and Bloch, B. (1991). Aromatic L-amino-acid decarboxylase (DOPA decarboxylase) gene expression in dopaminergic and serotonergic cells of the rat brainstem. $\mathrm{Neu}$ rosci. Lett. 127, 203-206.

Tomie, A., Aguado, A. S., Pohorecky, L. A., and Benjamin, D. (2000). Individual differences in Pavlovian autoshaping of lever pressing in rats predict stress-induced corticosterone release and mesolimbic levels of monoamines. Pharmacol. Biochem. Behav. 65, 509-517.

Van Leare, K., Goffin, K., Bormans, G., Casteels, C., Mortelmans, L., de Hoon, J., et al. (2009). Relationship of type 1 cannabinoid receptor availability in the human brain to novelty-seeking temperament. Arch. Gen. Psychiatry 66, 196-204.

Voon, V., Schoerling, A., Wenzel, S., Ekanayake, V., Reiff, J., Trenkwalder, C., et al. (2011a). Frequency of impulse control behaviours associated with dopaminergic therapy in restless legs syndrome. BMC Neurol. 11:117. doi:10.1186/1471-237711-117

Voon, V., Sohr, M., Lang, A. E., Potenza, M. N., Siderowf, A. D., Whetteckey, J., et al. (2011b). Impulse control disorders in Parkinson's disease: a multicenter case-control study. Ann. Neurol. 69, 986-996.

Voon, V., Thomsen, T., Miyasaki, J. M., de Souza, M., Shafro, A., Fox, S. H., et al. (2007). Factors associated with dopaminergic drug-related pathological gambling in Parkinson disease. Arch. Neurol. 64, 212-216.

Weintraub, D., Papay, K., and Siderowf, A. (2013). Screening for impulse control symptoms in patients with de novo Parkinson disease: a case-control study. Neurology 80, 176-180.

Weintraub, D., Sohr, M., Potenza, M. N., Siderowf, A. D., Stacy, M., Voon, V., et al. (2010). Impulse control disorders in Parkinson's disease: a crosssectional study of 3090 patients. Arch. Neurol. 67, 589-595.

Whone, A. L., Bailey, D. L., Remy, P., Pavese, N., and Brooks, D. J. (2004). A technique for standardized central analysis of 6-18F-Fluoro-L-DOPA PET data from a multicenter study. J. Nucl. Med. 45, 1135-1145.

Whone, A. L., Moore, R. Y., Piccini, P. P., and Brooks, D. J. (2003a). Plasticity of the nigropallidal pathway in Parkinson's disease. Ann. Neurol. 53, 206-213.

Whone, A. L., Watts, R. L., Stoessl, A. J., Davis, M., Reske, S., Nahmias, C., et al. (2003b). Slower progression of Parkinson's disease with ropinirole versus levodopa: the REAL-PET study. Ann. Neurol. 54, 93-101.

Winstanley, C. A., Theobald, D. E., Dalley, J. W., and Robbins, T. W. (2005). Interactions between serotonin and dopamine in the control of impulsive choice in rats: therapeutic implications for impulse control disorders. Neuropsychopharmacology 30, 669-682. 
Wolf, M. E., and Roth, R. H. (1990). Autoreceptor regulation of dopamine synthesis. Ann. N. Y. Acad. Sci. 604, 323-343.

Yau, W.-Y. W., Zubieta, J.-K., Weiland, B. J., Samudra, P. G., Zucker, R. A., and Heitzeg, M. M. (2012). Nucleus accumbens response to incentive stimuli anticipation in children of alcoholics: relationships with precursive behavioral risk and lifetime alcohol use. J. Neurosci. 32, 2544-2551.

Young, S. E., Stallings, M. C., Corley, R. P., Krauter, K. S., and Hewitt, J. K. (2000). Genetic and environmental influences on behavioral disinhibition. Am. J. Med. Genet. B. Neuropsychiatr. Genet. 96, 684-695.
Yu, Y., Panhuysen, C., Kranzler, H. R., Hesselbrock, V., Rounsaville, B., Weiss, R., et al. (2006). Intronic variants in the dopa decarboxylase (DDC) gene are associated with smoking behaviour in EuropeanAmericans and African-Americans. Hum. Mol. Genet. 15, 2192-2199.

Zald, D. H., Cowan, R. L., Riccardi, P., Baldwin, R. M., Ansari, M. S., Li, R., et al. (2008). Midbrain dopamine receptor availability is inversely associated with noveltyseeking traits in humans. J. Neurosci. 14372-14378.

Zhang, P., Ye, Y., Wang, X., Gelernter, J., Mai, J. Z., and Li, M. D. (2006). DOPA decarboxylase gene is associated with nicotine dependence. Pharmacogenomics 7, 1159-1166.

Zhu, M. Y., Juorio, A. V., Paterson, I. A., and Boulton, A. A. (1992). Regulation of aromatic L-amino acid decarboxylase by dopamine receptors in the rat brain. J. Neurochem. $58,636-641$.

Conflict of Interest Statement: The authors declare that the research was conducted in the absence of any commercial or financial relationships that could be construed as a potential conflict of interest.

Received: 28 September 2012; accepted: 07 February 2013; published online: 27 February 2013.
Citation: Lawrence AD, Brooks DJ and Whone AL (2013) Ventral striatal dopamine synthesis capacity predicts financial extravagance in Parkinson's disease. Front. Psychol. 4:90. doi: 10.3389/fpsyg.2013.00090

This article was submitted to Frontiers in Decision Neuroscience, a specialty of Frontiers in Psychology.

Copyright (c) 2013 Lawrence, Brooks and Whone. This is an open-access article distributed under the terms of the Creative Commons Attribution License, which permits use, distribution and reproduction in other forums, provided the original authors and source are credited and subject to any copyright notices concerning any third-party graphics etc. 